\section{Commentary: Patient frailty also drives long-term outcomes after R0 resection for lung cancer}

\author{
Benjamin R. Zambetti, MD, and \\ Thomas Ng, MD, FRCSC, FACS
}

The parsimonious Eurolung risk model was derived from the European Society of Thoracic Surgeons dataset to predict postoperative 30 -day morbidity and mortality. ${ }^{1}$ Brunelli and colleagues ${ }^{2}$ have applied this same risk model to examine long-term outcomes of overall and diseasespecific survival, finding the Eurolung score to be an independent predictor of both, even after adjusting for tumor size and nodal involvement. Although this score provides compelling information regarding early postoperative morbidity and mortality, and now overall and diseasespecific survival, the model seems to be a surrogate for frailty, which can drive patients' long-term outcomes.

In this study, 1359 patients who underwent R0 anatomic resection for non-small cell lung cancer were examined and assigned a Eurolung score, which is a score based on 6 components: age, postoperative predicted forced expiratory volume in 1 second, body mass index, gender, open surgery (vs minimally invasive) and pneumonectomy (vs lesser resection). For analysis, the patients were categorized into 4 groups of ascending score, with a higher score/category representing higher risk. Examining these 6 components individually, one can easily see how each may correlate with frailty; the increase in age, the decrease postoperative predicted forced expiratory volume in 1 second, the decrease in body mass index, male gender, and the increased traumas of open surgery and pneumonectomy. One may expect that frailty would be associated with overall survival, but from this study, frailty was also found be

\footnotetext{
From the Division of Thoracic Surgery, University of Tennessee Health Science Center College of Medicine, Memphis, Tenn.

Disclosures: The authors reported no conflicts of interest.

The Journal policy requires editors and reviewers to disclose conflicts of interest and to decline handling or reviewing manuscripts for which they may have a conflict of interest. The editors and reviewers of this article have no conflicts of interest.

Received for publication June 27, 2020; revisions received June 27, 2020; accepted for publication June 28, 2020; available ahead of print July 14, 2020.

Address for reprints: Thomas Ng, MD, FRCSC, FACS, Division of Thoracic Surgery, University of Tennessee Health Science Center College of Medicine, 1325 Eastmoreland Ave, Suite 460, Memphis, TN 38104 (E-mail: tng4@uthsc.edu).

J Thorac Cardiovasc Surg 2021;161:787-8

$0022-5223 / \$ 36.00$

Copyright (c) 2020 by The American Association for Thoracic Surgery

https://doi.org/10.1016/j.jtcvs.2020.06.115
}

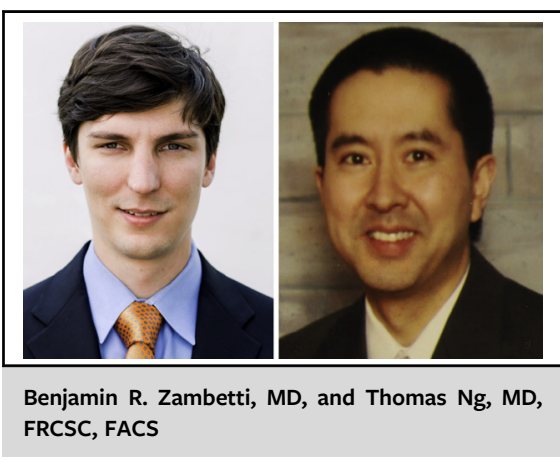

CENTRAL MESSAGE

The Eurolung risk model is a useful adjunct for counseling patients on long-term survival after lung cancer surgery, although it may represent the effects of poor health and frailty on outcomes.

associated with disease-specific survival, which has significant implications because frailty may be a marker of disease burden and frail patients are less likely to tolerate additional therapy after surgery. The literature supports the results found by Brunelli and colleagues ${ }^{2}$ : many of the 6 components of the Eurolung score have also been shown by other investigators to be associated with long-term survival. ${ }^{3-5}$

Limitations of this study are few but worth mentioning. The follow-up is short, with median at just more than 2 years. Patient comorbidity is not accounted for, which has previously been shown to be an independent factor associated with long-term survival. ${ }^{6}$ The parsimonious Eurolung risk model was adjusted from its original version, eliminating some of its comorbidity components and tailored to examine short-term outcomes; thus, it may be in need of recalibration to more accurately assess longterm outcomes.

Brunelli and colleagues ${ }^{2}$ provide data to confirm what thoracic surgeons have known for some time, that outcomes-both short and long-term-are poor in frail patients. The study also has great potential to influence clinical practice. The Eurolung risk model can now shape the conversation that we have with our patients when counseling them on the options of therapy. Long-term outcomes are not only dependent on disease stage and treatment, but also on patient frailty. With the availability of nonsurgical treatments for early-stage lung cancer, such as stereotactic 
radiation and ablation procedures, the Eurolung risk model becomes an important tool to help us select the most appropriate therapy for our patients.

\section{References}

1. Brunelli A, Cicconi S, Decaluwe H, Szanto Z, Falcoz PE. Parsimonious Eurolung risk models to predict cardiopulmonary morbidity and mortality following anatomic lung resections: an updated analysis from the European Society of Thoracic Surgeons database. Eur J Cardiothorac Surg. 2020;57:455-61.

2. Brunelli A, Chaudhuri N, Kefaloyannis K, Milton R, Pompili C, Tcherveniakov P, et al. Eurolung risk score is associated with long-term survival after curative resection for lung cancer. J Thorac Cardiovasc Surg. 2021;161: $776-86$.
3. Ferguson MK, Watson S, Johnson E, Vigneswaran WT. Predicted postoperative lung function is associated with all-cause long-term mortality after major lung resection for cancer. Eur J Cardiothorac Surg. 2014;45:660-4.

4. Chang MY, Mentzer SJ, Colson YL, Linden PA, Jaklitsch MT, Lipsitz SR, et al. Factors predicting poor survival after resection of stage IA non-small cell lung cancer. J Thorac Cardiovasc Surg. 2007;134:850-6.

5. Shepshelovich D, Xu W, Lu L, Fares A, Yang P, Christiani D, et al. Body mass index (BMI), BMI change, and overall survival in patients with SCLC and NSCLC: a pooled analysis of the international lung cancer consortium. J Thorac Oncol. 2019; 14:1594-607.

6. Yang CC, Fong Y, Lin LC, Que J, Ting WC, Chang CL, et al. The age-adjusted Charlson comorbidity index is a better predictor of survival in operated lung cancer patients than the Charlson and Elixhauser comorbidity indices. Eur J Cardiothorac Surg. 2018;53:235-40.
See Article page 776.

\section{Commentary: Eurolung score as a predictor of long-term survival: It is not all about the tumor}

\author{
Taryne Imai, MD, ${ }^{\mathrm{a}}$ and Benny Weksler, $\mathrm{MD}^{\mathrm{b}}$
}

Thoracic surgeons must care for an aging population with lung cancer, and lung resection in elderly patients has become relatively common. ${ }^{1}$ With increased patient age comes increased comorbidities and frailty. It is intuitive that survival in elderly patients with lung cancer is not dependent on traditional TNM staging alone. Scores evaluating comorbid conditions and frailty have been shown to predict surgical mortality and also may correlate with long-term survival. ${ }^{2-5}$ These studies illuminate the need for a thorough evaluation of candidates for lung resection that includes careful assessment of nononcologic measures that may determine survival independent of TNM cancer staging.

From the a Division of Thoracic Surgery, Department of Surgery, Cedar Sinai Medical Center, Los Angeles, Calif and ${ }^{\mathrm{b}}$ Division of Thoracic and Esophageal Surgery, Department of Thoracic and Cardiovascular Surgery, Allegheny General Hospital, Pittsburgh, $\mathrm{Pa}$.

Disclosures: Dr Weksler: proctor for Intuitive Surgery; speaker for AstraZeneca. The other author reported no conflicts of interest.

The Journal policy requires editors and reviewers to disclose conflicts of interest and to decline handling or reviewing manuscripts for which they may have a conflict of interest. The editors and reviewers of this article have no conflicts of interest.

Received for publication July 3, 2020; revisions received July 3, 2020; accepted for publication July 6, 2020; available ahead of print July 11, 2020.

Address for reprints: Benny Weksler, MD, Division of Thoracic and Esophageal Surgery, Department of Thoracic and Cardiovascular Surgery, Allegheny General Hospital, 320 E North Ave, 14th Floor, South Tower, Pittsburgh, PA 15212 (E-mail: benny.weksler@ahn.org).

J Thorac Cardiovasc Surg 2021;161:788-9

$0022-5223 / \$ 36.00$

Copyright $₫ 2020$ Published by Elsevier Inc. on behalf of The American Association for Thoracic Surgery

https://doi.org/10.1016/j.jtcvs.2020.07.006
Check for updates

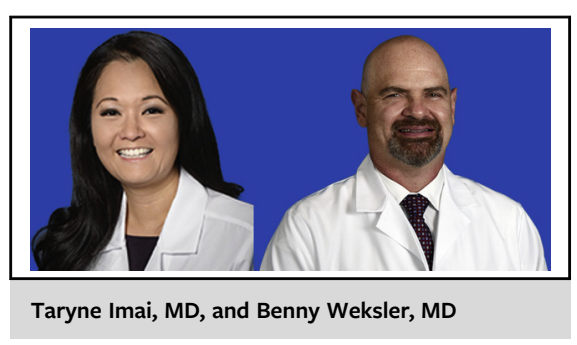

CENTRAL MESSAGE

The Eurolung score may corre-

late with overall and disease-

specific survival after curative

resection of lung cancer. This

may assist surgeons during

shared decision making with

patients.

In their article in this issue of the Journal, Brunelli and colleagues ${ }^{6}$ provide a retrospective review of a prospectively collected database evaluating the Eurolung risk score and patient survival after curative resection for lung cancer. Although the Eurolung score was developed to stratify the risk of postoperative 30-day morbidity and mortality in patients undergoing lung resection, the authors applied the model to investigate its association with long-term survival. ${ }^{6}$ A total of 1359 consecutive patients who underwent potentially curative (R0) anatomic lung resection for non-smallcell lung cancer were analyzed, with a median follow-up of 802 days. Patients were categorized into 4 risk classes 